\title{
Calcitonin-secreting neuroendocrine neoplasms of the lung: a systematic review and narrative synthesis
}

\author{
David C Llewellyn ${ }^{1}$, Rajaventhan Srirajaskanthan ${ }^{2,3}$, Royce P Vincent ${ }^{3,4}$, Catherine Guy ${ }^{5}$, Eftychia E Drakou ${ }^{6}$, \\ Simon J B Aylwin ${ }^{1,2}$, Ashley B Grossman ${ }^{7,8,9}$, John K Ramage ${ }^{2,3}$ and Georgios K Dimitriadis 1 1,10 \\ 'Department of Endocrinology ASO/EASO COM, King's College Hospital NHS Foundation Trust, Denmark Hill, London, UK \\ ${ }^{2}$ Neuroendocrine Tumour Unit, Kings Health Partners ENETS Centre of Excellence, Denmark Hill, London, UK \\ ${ }^{3}$ Faculty of Life Sciences and Medicine, Kings College London, London, UK \\ ${ }^{4}$ Department of Clinical Biochemistry, King's College Hospital NHS Foundation Trust, Denmark Hill, London, UK \\ ${ }^{5}$ Department of Cellular Pathology, Royal Sussex County Hospital, Eastern Road, Brighton, UK \\ ${ }^{6}$ Department of Clinical Oncology, Guy's Cancer Centre - Guy's and St Thomas' NHS Foundation Trust, Great Maze Pond, London, UK \\ 7Oxford Centre for Diabetes, Endocrinology and Metabolism, University of Oxford, Oxford, UK \\ ${ }^{8}$ Barts and the London School of Medicine, Centre for Endocrinology, William Harvey Institute, London, UK \\ ${ }^{9}$ Neuroendocrine Tumour Unit, Royal Free Hospital, London, UK \\ ${ }^{10}$ Faculty of Life Sciences and Medicine, School of Life Course Sciences, Obesity Immunometabolism and Diabetes Group, King's College London, \\ London, UK
}

Correspondence should be addressed to G K Dimitriadis: g.dimitriadis@nhs.net

\begin{abstract}
Calcitonin-secreting neuroendocrine neoplasms of the lung are rare, with few cases reported in the literature. Differentiating between medullary thyroid carcinoma and an ectopic source of calcitonin secretion can represent a complex diagnostic conundrum for managing physicians, with cases of unnecessary thyroidectomy reported in the literature. This manuscript reports a case of ectopic hypercalcitonaemia from a metastatic neuroendocrine neoplasm of the lung with concurrent thyroid pathology and summarises the results of a systematic review of the literature. Medical Literature Analysis and Retrieval System Online, Excerpta Medica, Cochrane Central Register of Controlled Trials, ClinicalTrials.gov and SCOPUS databases were systematically and critically appraised for all peer reviewed manuscripts that suitably fulfilled the inclusion criteria established a priori. The protocol for this systematic review was developed according to the Preferred Reporting Items for Systematic review and Meta-Analysis Protocols, and followed methods outlined in The Cochrane Handbook for Systematic Reviews of Interventions. This systematic review is registered with PROSPERO. It is vital to consider diagnoses other than medullary thyroid carcinoma when presented with a patient with raised calcitonin, as it is not pathognomonic of medullary thyroid carcinoma. Lung neuroendocrine neoplasms can appear similar to medullary thyroid carcinoma histologically, they can secrete calcitonin and metastasize to the thyroid. Patients with medullary thyroid carcinoma may show stimulated calcitonin values over two or more times above the basal values, whereas calcitonin-secreting neuroendocrine neoplasms may or may not show response to stimulation tests. The present review summarises existing evidence from cases of ectopic hypercalcitonaemia to lung neuroendocrine neoplasms.
\end{abstract}

\author{
Key Words \\ - calcitonin \\ - ectopic \\ - paraneoplastic \\ - neuroendocrine neoplasm \\ - lung \\ - systematic review
}

https://ec.bioscientifica.com

https://doi.org/10.1530/EC-21-0071
() 2021 The authors Published by Bioscientifica Ltd

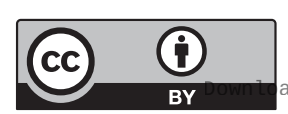

This work is licensed under a Creative Commons Attribution 4.0 International License. ded from Bioscientifica.com at 04/26/2023 10:32:39AM
Endocrine Connections (2021) 10, 447-461 


\section{Introduction}

Neuroendocrine neoplasms (NENs) are a group of tumours that can often synthesise and secrete biologically active substances. This can lead to an array of clinical presentations, also referred to as paraneoplastic syndromes (PNS) (1).

PNS can occur as either the neoplasms acquire the ability to secrete a variety of biologically active substances, or by cross-reactivity between neoplastic and normal tissue $(1,2,3,4)$. The secretions from neoplasms can be eutopic, meaning from an expected site of origin which would usually secrete such a substance, or ectopic, referring to cells that would not normally be associated with secretion of that substance. The ectopic secretion of biological substances such as peptides, amines or cytokines isec more commonly seen by neoplasms that are formed in the gut $(2,4,5)$. Endocrine PNS is the term used when PNS is from the ectopic secretion of a hormone, and can lead to diagnostic uncertainty, as it can manifest with symptoms identical to a neoplasm in the expected site of origin $(4,6,7)$.

Calcitonin (CTN) is secreted from parafollicular cells located in the thyroid gland, but also can be present in the lung, bladder, small intestine, liver, thymus and parathyroid glands. Parafollicular cells are part of the neuroendocrine system and originate from primordial $\mathrm{C}$ cells $(8,9)$. The gene $C A L C-1$ creates procalcitonin, which is cleaved by a convertase enzyme to create CTN (5). In in vitro experimental models, CTN has a temporary effect on impairing osteoclast function by reducing its motility, inhibiting carbonic anhydrase II and preventing the development of mature osteoclasts. This, along with its effects on tubular epithelium within the kidney, reduces serum calcium and phosphate levels (8). However, the significance and biological role of CTN remains elusive.

High serum CTN concentrations may be suggestive of MTC but are not pathognomonic (9). MTC is a NEN originating from the thyroid and associated with eutopic secretion of CTN. However, CTN can also be raised due to chronic renal failure, pernicious anaemia, hepatic cirrhosis, various medications, extra-thyroid neoplasms, false-positive CTN assay laboratory results, lower respiratory tract infections, smoking, chronic inflammatory conditions of the lung, and any condition increasing gastrin or calcium such as hyperparathyroidism or Zollinger-Ellison syndrome $(7,8,10,11)$. These conditions tend to cause a moderate rise in CTN compared to MTC. Extra-thyroidal NENs, however, lead to a diagnostic dilemma as they can be associated with similar concentrations of CTN to MTC. Extra-thyroidal sources associated with abnormal CTN concentration have been observed in NENs within the pancreas, parathyroid glands, larynx, oesophagus, thymus, lung, small intestine, liver, bladder and adrenals, all of which can resemble MTC histologically $(3,5,10,12)$.

Around $1 \%$ of normal pulmonary tissue is made up of neuroendocrine cells, which can be solitary cells throughout the lung or form in clusters called neuroepithelial bodies $(13,14,15)$. They remain in adult lungs, and continue to secrete bioactive substances such as calcitonin, calcitonin gene-related peptide, serotonin, chromogranin A, and gastrin-related peptide $(15,16$, 17). Physiological stimuli, such as hypoxia, can lead to such agents being secreted (16), which may be why Machens et al. report fluctuations of hypercalcitonaemia in patients with chronic lung disease (10). There is speculation that neuroendocrine cells are the origin of lung NENs, but as we do not yet have evidence of the events of early cell change into neoplasm, this cannot be claimed definitively (16). However, around 25\% of lung carcinomas (mainly small and large cell lung carcinomas) can develop neuroendocrine features and may be associated with endocrine PNS $(7,14)$. The development of an endocrine PNS may be what initially leads to the diagnosis of a carcinoma, or its recurrence in cases of patients with known malignancy $(4,18)$.

Extra-thyroidal CTN-secreting NENs can be indistinguishable from MTC in terms of immunohistochemical and biochemical profiles $(4,6)$. Due to the above similarities, biopsies with immunohistochemical characteristics of MTC, along with serum hypercalcitonaemia, could lead to an incorrect diagnosis of MTC. There have been cases of inappropriate thyroidectomy performed in patients with hypercalcitonaemia of extra-thyroidal origin due to concern of MTC $(6,8)$. We now report the diagnostic work-up of a patient found to have a lung lesion and a biopsied gluteal mass with histological appearances of MTC, in the context of morphological thyroid gland abnormalities and concurrent hypercalcitonaemia, and review the relevant literature.

\section{Methodology}

This protocol was developed according to the Preferred Reporting Items for Systematic review and Meta-Analysis Protocols (PRISMA-P), and followed methods outlined in The Cochrane Handbook for Systematic Reviews of Interventions (15). This systematic review has been 
registered with PROSPERO (International Prospective Register of Systematic Reviews) with registration number CRD42021228917.

\section{Search strategy}

Two reviewers (D L and G K D) conducted systematic searches of the following databases: Medical Literature Analysis and Retrieval System Online (MEDLINE), Excerpta Medica (EMBASE), Cochrane Central Register of Controlled Trials (CENTRAL), ClinicalTrials.gov, SCOPUS databases. Our key MeSH (Medical Subject Heading) search terms were; "paraneoplastic" $O R$ "ectopic" $O R$ "neuroendocrine" AND "calciton..." AND "lung".

Moreover, reference lists of selected articles and other literature sources were browsed to ensure a comprehensive literature search was completed. None of the database searches filtered results based on year of publication date, and the last search was carried out in January 2021.

\section{Study selection}

Expert opinion manuscripts, letters to the editor, commentaries, conference papers, animal studies, metaanalyses, and articles not in English, were excluded. Data were only included on adults (18 years or older), men and non-pregnant women. Articles were included if they examined from a lung lesion. No restrictions were made regarding the intervention type where a study took place, the number of participants or the duration of follow up. Covidence systematic review software (Veritas Health Innovation, Melbourne, Australia; http://www.covidence. org) was used for manuscript screening and extraction. Publications were initially screened for any duplicates before being assessed independently and in parallel by two reviewers. Any conflicts regarding the inclusion of a study were met with discussion and consensus. If an agreement had not been reached, arbitration by a third reviewer was utilised.

\section{Data extraction}

Data were extracted independently by two reviewers following the Cochrane Public Health Group Data Extraction and Assessment Template to construct our own data extraction template that was pilot-tested and systematically used for each article. Data extracted included; study description (e.g. title, primary author, publication year, type of study, number of participants, type of lung CTN producing neoplasm and follow-up duration). The primary outcome was the incidence of calcitonin-secreting lung NENs.

\section{Quality assessment}

Each study was assessed for bias using the NewcastleOttawa scale for observational studies. Studies were evaluated on eight factors, categorised into three groups: selection (including whether the cohort is representative of the population), comparability (assessed on grounds of study design and the analysis performed) and outcome (i.e. the assessment of outcome, follow-up rate and adequacy follow-up period).

Stars were awarded per category, with a maximum of four, two and three stars possible for the 'selection', 'comparability' and 'outcome' categories respectively. By following the guidelines of the Newcastle-Ottawa scale (16), two reviewers assessed the studies to be of poor (3 stars or less), fair (4-6 stars) or good (7-9 stars) quality.

\section{Data synthesis and statistical analysis}

Heterogeneity was visually inspected, and due to the high variability and insufficient data results were not pooled into a meta-analysis, and a narrative synthesis was conducted instead.

\section{Results}

Our advanced search produced 327 manuscripts that were imported for screening against predefined criteria. There were no duplicate studies and all 327 manuscripts were screened against title and abstract which resulted in 29 manuscripts progressing to a full-text assessment. A further 6 manuscripts were excluded as they were not in English, resulting in 23 eligible manuscripts.

The Preferred Reporting Items for Systematic Reviews and Meta-Analyses (PRISMA-P) flow diagram is shown in Fig. 1, outlining the outcomes of the screening proce

\section{Case report}

A 72-year-old Caucasian female presented in January 2020 with weight loss and a gluteal mass. She had no major co-morbidities and was not on any regular medications. She had noted gradual weight loss which had started since August 2019, with recurrent ear infections.

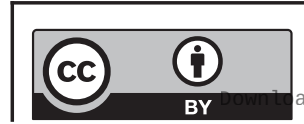

This work is licensed under a Creative Commons Attribution 4.0 International License. ded from Bioscientifica.com at 04/26/2023 10:32:39AM 


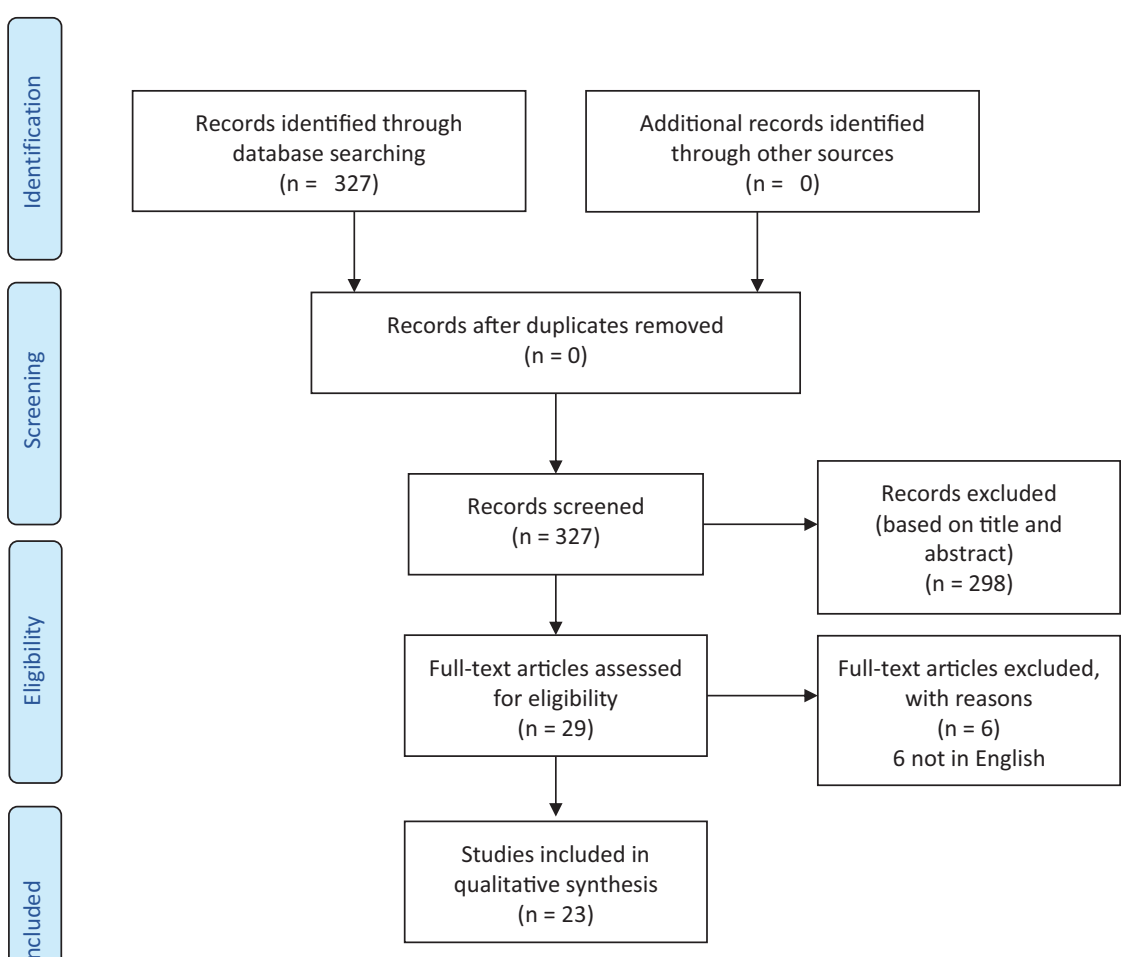

\section{Figure 1}

Flow diagram demonstrating the breakdown of the screening process.

She suffered with intermittent loose stools but no flushing, later diagnosed as terminal ileitis.

She subsequently had a chest, abdomen and pelvis (CAP) contnrast-enhanced CT which showed bilateral pulmonary emboli, and a large $4 \times 4.5 \mathrm{~cm}$ mass within the right upper lobe of the lung (Fig. 2). Furthermore, there was evidence of a large retrosternal thyroid goitre and no further evidence of any intra-abdominal abnormalities. An enhancing lesion in the left gluteus was seen, thought to be in keeping with a soft tissue metastasis.

She was referred for a ${ }^{18}$ fluoro-deoxyglucose PET $\left({ }^{18}\right.$ FDG-PET) which showed normal metabolic activity throughout the thyroid, including the retrosternal goitre. There was intense uptake (SUV $\max >4.5$ ) within the $4.5 \mathrm{~cm}$ right upper lobe lung and gluteal mass (Fig. 3).

A biopsy of the left gluteal lesion showed fibrofatty tissue infiltrated with malignant cells arranged predominantly with solid sheets. The cells had abundant eosinophilic cytoplasm and eccentric nuclei with frequent nuclear inclusions noted (Fig. 4A). Malignant cells were positive for cytokeratin AE1/3, TTF1, PAX-8, synaptophysin and calcitonin, with granular staining for CEA (Fig. 4B). Staining for chromogranin A, S100, Melan A, CD45, Napsin A, thyroglobulin and p40 was negative (Fig. 4C). The Ki-67 proliferation index was high at $84 \%$. The morphology and immunophenotype were most in keeping with metastatic medullary thyroid carcinoma, although other metastatic neuroendocrine neoplasms could not be completely excluded.

She was also referred for a neck ultrasound scan (USS) which showed a $2.6 \mathrm{~cm}$ left confluence of spongiform

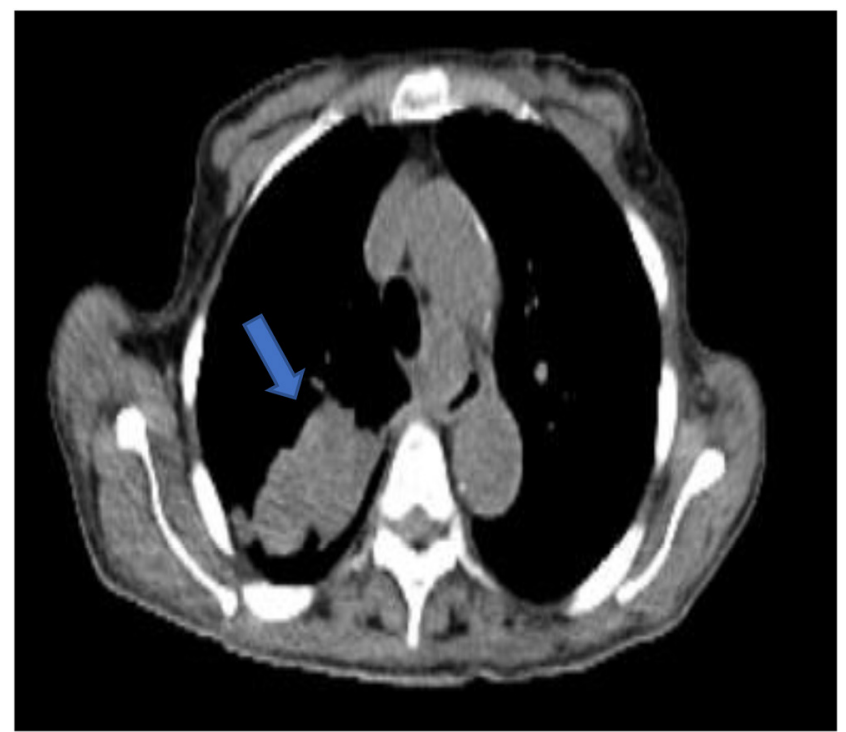

Figure 2

CT scan with transverse plane view of the $4 \times 4.5 \mathrm{~cm}$ right upper lobe lung lesion. 


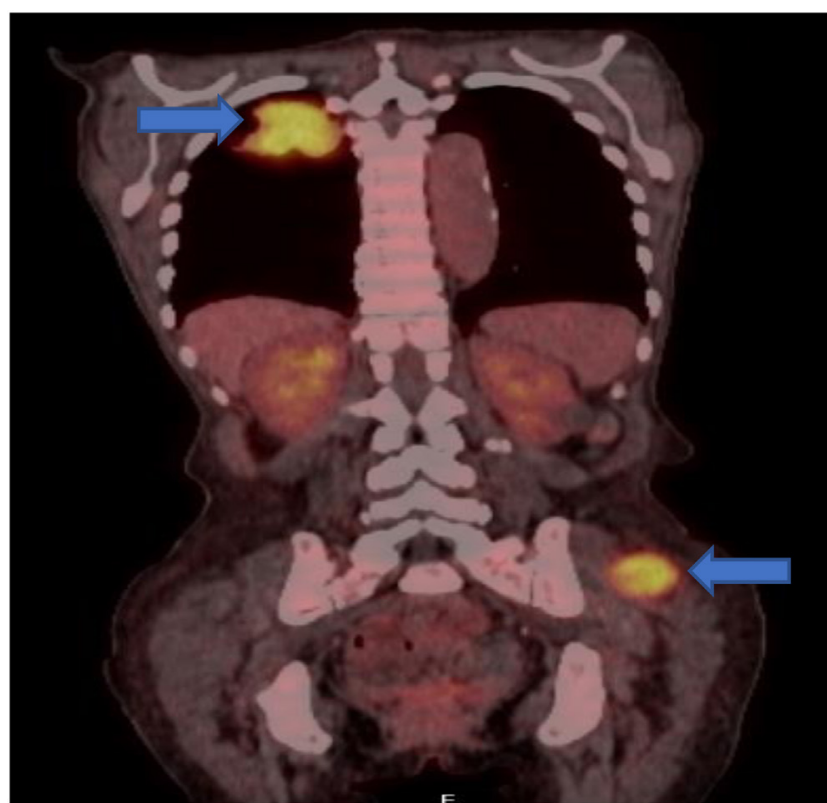

Figure 3

${ }^{18}$ FDG-PET coronal CT displaying two avid lesions, in the right upper lobe and left gluteal region.

thyroid nodules, with hypoechoic halos (U2). There was no cervical lymphadenopathy (Fig. 5).

Following discussion in the thyroid cancer multidisciplinary team meeting, her left thyroid confluence was upgraded to U4 using British Thyroid Association (BTA) guidelines (Table 1) (12). Serum calcitonin was measured and fine-needle aspiration (FNA) of the thyroid confluence was performed to help rule out MTC. Using BTA classification, cytology was in keeping with a Thy-2 sample, which maps directly to the American Bethesda Categories and means it was non-neoplastic (Table 2) (12).

Calcitonin was $3900 \mathrm{pg} / \mathrm{mL}$ (normal range 0-4.8), CEA $4.6 \mu \mathrm{g} / \mathrm{L}$ (normal range 0-3.8). She was reviewed in the clinic, by which time she had already been on prednisolone $10 \mathrm{mg}$ daily to try and stimulate her appetite. While in clinic, she reported significant polydipsia and polyuria, and her serum blood glucose was $21 \mathrm{mmol} / \mathrm{L}$. She was admitted for urgent inpatient management of steroid-induced diabetes.

While an inpatient, she was also referred for a ${ }^{68} \mathrm{Ga}$-DOTATATE PET/CT scan which showed multiple sites of progression with pleural and nodal disease (Fig. 6). The finding was concerning of an upper right lobe lung primary with extensive right pleural and possibly solitary left pleural, nodal (above and below the diaphragm), and soft tissue (posterior to left psoas muscle ad inter left gluteal muscle) metastases.
It was decided that, considering the results of gluteal mass histology, thyroid nodule cytology and imaging, the most likely diagnosis was not MTC but that of a neuroendocrine lung neoplasm, grade 3 . This patient deteriorated rapidly and died of complications before any further interventions were possible.

\section{Discussion}

CTN-secreting NENs are rare, with few reported cases in the last 20 years. While small cell lung carcinomas (SCLC) are more commonly associated with ectopic CTN secretion, a review by Bondy et al. suggested that in $51 \%$ of cases it is secondary to SCLC, $20 \%$ of squamous cell, $33 \%$ to adenocarcinoma and 33\% to large cell lung carcinomas (LCLC) (19). As patients with ectopic CTN secretion may not display overt clinical symptoms, they might not be tested for serum CTN and this may be one reason for the low number of reported cases. Another reason for the low number of reported cases may be that raised CTN is not associated with characteristic symptoms distinguishing this from other PNS.

Reported symptoms associated with raised CTN could be diarrhoea, flushing, metabolic alkalosis with hypokalaemia, hypocalcaemia, hypomagnesaemia, hypophosphataemia and hyperglycaemia (3, 20). Nozières et al. showed that only one-third of the patients with significantly raised CTN concentration above $100 \mathrm{ng} / \mathrm{L}$ had symptoms such as profuse diarrhoea and deranged electrolytes such as hypokalaemia, hypophosphataemia, hypocalcaemia and metabolic alkalosis (4). There are multiple other neuroendocrine neoplasms causing diarrhoea such as gastrinomas, VIPomas, glucagonomas, somatostatinomas and the carcinoid syndrome, as well as medullary thyroid cancer and hypercalcitonaemia secreted from the pancreas causing Verner-Morrison syndrome (20). In the reported cases, when patients with CTN-secreting lung NENs have clinical symptoms, there is usually co-secretion of other biologically active substances, and it is these substances that most likely explain the symptoms rather than the raised CTN $(2,3$, $5,7,20)$.

Evidence that the frequency of hypercalcitonaemia may be higher than expected comes from Tsutsumi et al., who found 10 out of 45 SCLC patients were CTN immunoreactive, and 14 out of 32 patients with bronchial carcinoid had CTN immunoreactivity on histopathological examination (21). Interestingly, their immunohistochemical studies demonstrated that

This work is licensed under a Creative Commons Attribution 4.0 International License. 

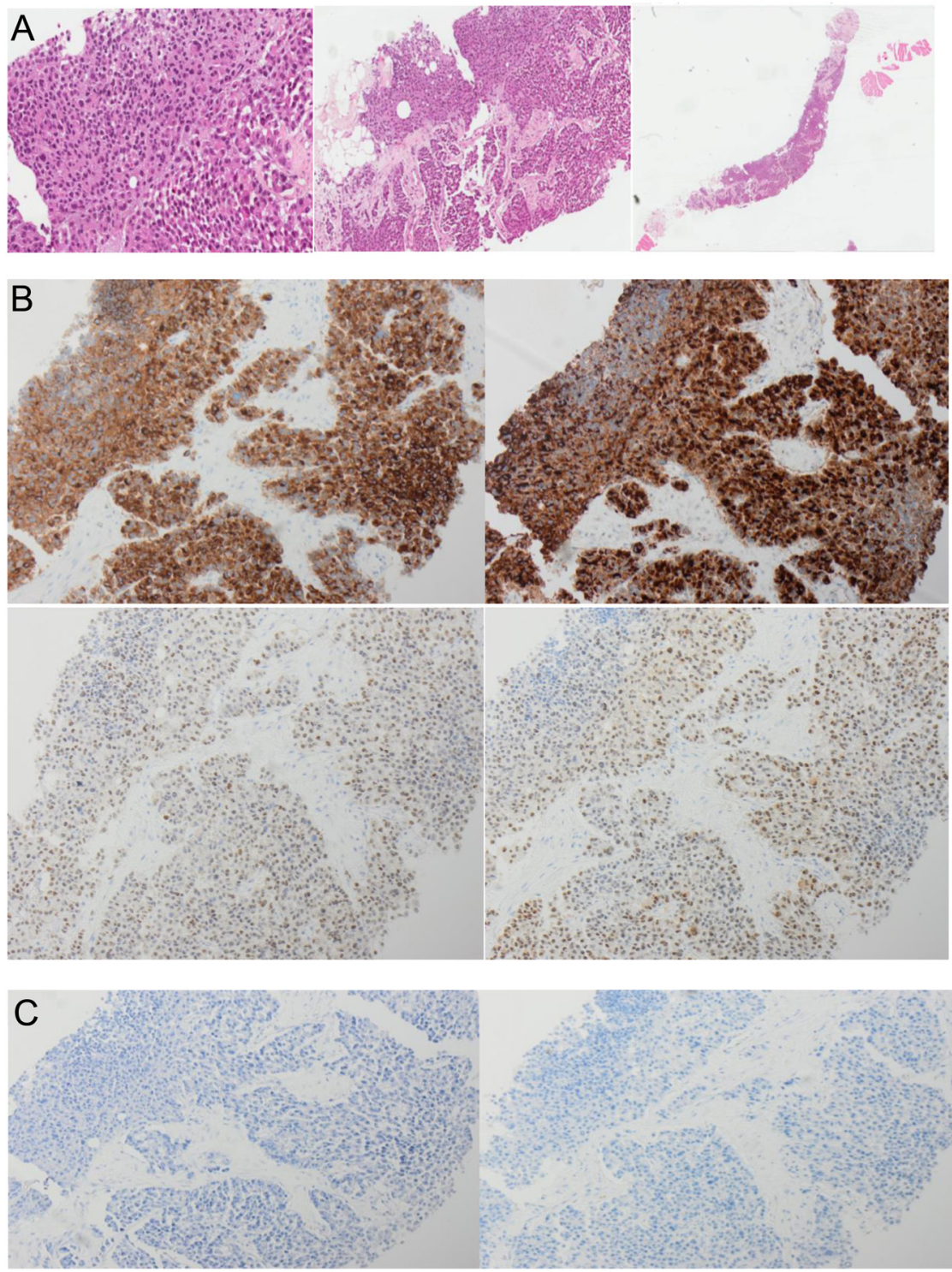

\section{Figure 4}

(A) Haematoxylin \& eosin staining of the left gluteal lesion composed of sheets of cells with abundant eosinophilic cytoplasm and eccentric nuclei with stippled chromatin, some with nuclear pseudo-inclusions. Twenty-five mitotic figures $/ 2$ mm slides. (B) Positive immunoperoxidase staining, $\times 100$ magnification, A: Synaptrophysin, B: Calcitonin, C: PAX8, D: TTF1. (C) Negative immunoperoxidase staining, $\times 100$ magnification, A: thyroglobulin, B: chromogranin. bronchial carcinoids appear to imitate foetal or neonatal lung in terms of calcitonin/calcitonin gene-related peptide expression. However, it was not known whether these patients had raised serum CTN concentrations. A significant proportion of lung neoplasms from that study were tested histologically and appeared to have the ability to express CTN, albeit patients were more often clinically asymptomatic (21).

A summary of the study characteristics that were included in our systematic review are included in Table 3. It is important to note that the most significant studies were performed before 1995: manuscripts published after 1995 are mostly case reports or small case series. A possible explanation for this is the method CTN was tested in the past. The initial approach was using RIA, which lacked sensitivity and specificity, and so this led to a two-sided IRMA developed in the late 1980s (8). In the early 2000s, there was a movement to fluorescent and chemiluminescent tests, which were more accurate. Enzyme-linked immunoassay (ELISA) technique was used, but an issue with ELISA was heterophilic antibody interference, associated with false positives or higher than actual values (8). One of the latest developments is the electrochemiluminescence immunoassay (ECLIA), which allows for a prompt and accurate diagnosis (8). This may be a reason why when large cohorts of patients with various NENs are randomly screened for CTN concentrations, such as with Daskalakis et al. (2), the percentage of them with hypercalcitonaemia is considerably less than several decades ago.

Coombes et al., Ellison et al. and Hillyard et al. published some of the earlier studies demonstrating that

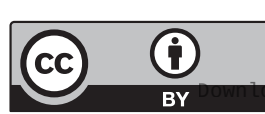

This work is licensed under a Creative Commons Attribution 4.0 International License. 


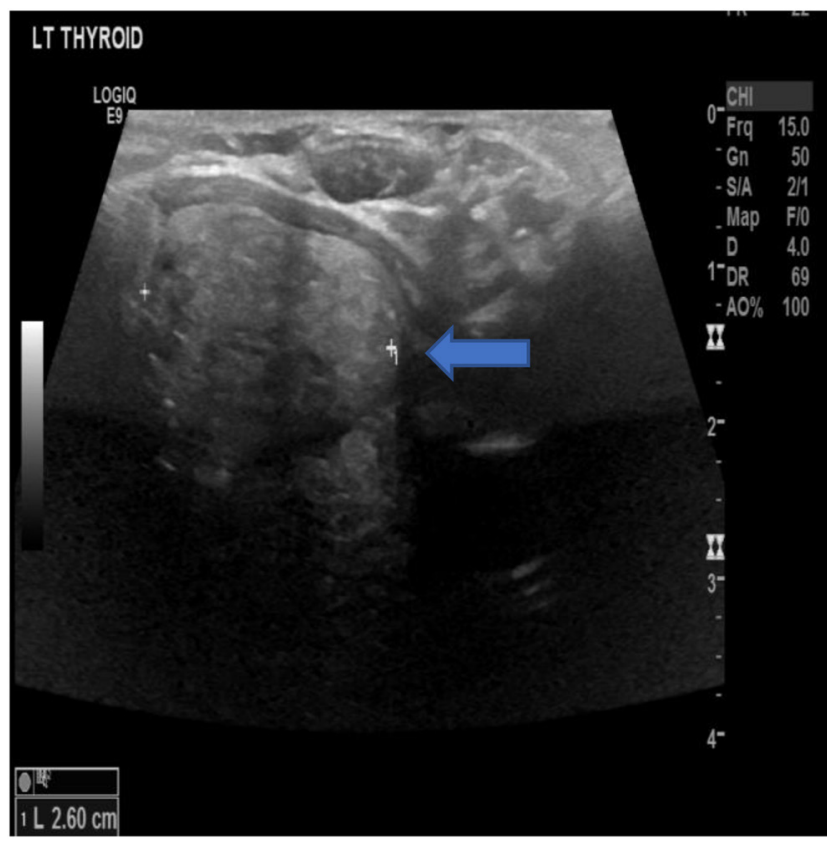

\section{Figure 5}

Thyroid USS demonstrating a $2.6 \mathrm{~cm}$ left confluence of spongiform thyroid nodules, with hypoechoic halos (U2). No cervical lymphadenopathy.

lung carcinomas can lead to ectopic secretion of CTN $(22,23,24)$. Coombes et al. showed that, in 8 out of 11 patients with SCLC in their study, there was ectopic CTN secretion (22).
Silva et al. showed that $52 \%$ of their 61 patients had hypercalcitonaemia (25). They also demonstrated that if the patient had a clinical response to treatment, this would be mirrored by a decrease in CTN concentration. Hansen et al. measured CTN concentrations in 75 patients with SCLC and found elevated CTN in 48 patients (26). Multiple patients in this study also had co-secretion of either ACTH or vasopressin (ADH). Hansen et al. found that there was no correlation with CTN and stage of disease, meaning higher CTN concentrations were not associated with more extensive disease (26).

Hansen et al. questioned whether previous studies reporting on the incidence of hypercalcitonaemia in their cohorts was due to infiltrative bone disease (27). None of the 74 patients from their cohort had hypercalcaemia, albeit two-thirds had hypercalcitonaemia. They found that when comparing different stages of the disease, there was no significant difference in CTN concentration, and that bone metastases did not lead to CTN elevations. CTN concentrations were in the range expected for MTC. In another study, Hansen et al. found that CTN concentration was not predicting response to treatment comparing responders to non-responders (28).

Hansen et al. performed a detailed follow-up of patients with hypercalcitonaemia (29). Their study had three arms and all patients in their study had SCLC. In the first arm, 6 patients with raised CTN concentrations had blood tests taken prior to their chemotherapy which consisted of

Table $1 \cup$ grading of thyroid nodules based on ultrasound imaging (18).

\begin{tabular}{|c|c|c|}
\hline U1 & U2 & U3 \\
\hline Normal & Benign & Indeterminate/e \\
\hline \multirow{6}{*}{$\begin{array}{l}\text { Normal } \\
\text { thyroid } \\
\text { tissue }\end{array}$} & Halo & Homogenous \\
\hline & Iso-echoic or mildly hyperechoic & $\begin{array}{l}\text { Hyper-echoic sol } \\
\text { (follicular lesion }\end{array}$ \\
\hline & Cystic change \pm ring & \\
\hline & $\begin{array}{l}\text { Down sign micro-cystic/ } \\
\text { spongiform. Peripheral }\end{array}$ & Equivocal echoge \\
\hline & Egg shell calcification & $\begin{array}{l}\text { Cystic change mi } \\
\text { vascularity }\end{array}$ \\
\hline & Peripheral vascularity & \\
\hline $\begin{array}{l}\text { No follow-up } \\
\text { required }\end{array}$ & $\begin{array}{l}\text { No follow-up required - routine } \\
\text { FNAC not recommended } \\
\text { unless high clinical suspicion } \\
\text { of thyroid cancer }\end{array}$ & FNAC \\
\hline \multicolumn{3}{|c|}{ FNAC, fine-needle aspiration cytology. } \\
\hline \multicolumn{2}{|c|}{$\begin{array}{l}\text { https://ec.bioscientifica.com } \\
\text { https://doi.org/10.1530/EC-21-0071 }\end{array}$} & $\begin{array}{l}\text { (c) } 2021 \text { The authors } \\
\text { by Bioscientifica Ltd }\end{array}$ \\
\hline
\end{tabular}

U4

Suspicious Solid

Hypo-echoic or very hypo-echoic

Disrupted

peripheral

calcification

lobulated outline spongiform. Peripheral Egg shell calcification

Peripheral vascularity

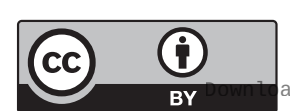

This work is licensed under a Creative Commons Attribution 4.0 International License. ded from Bioscientifica.com at 04/26/2023 10:32:39AM 

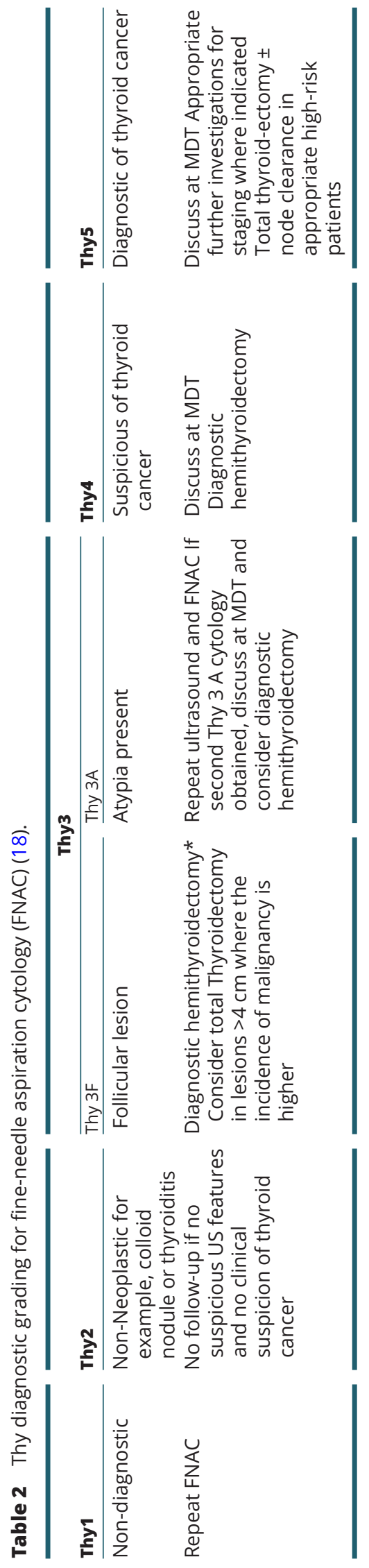

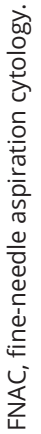

cyclophosphamide and vincristine. Blood samples were then repeated at regular intervals over a week. 4 out of 6 patients had raised baseline CTN concentrations, and in those 4 patients there was a significant decrease in CTN levels at 1 week following treatment. The second arm had baseline blood tests prior to chemotherapy, 3-6 months later, and then again if there was evidence of disease relapse: 11 patients in this arm had baseline CTN concentrations exceeding $79 \mathrm{pg} / \mathrm{mL}$ and tumour partial or complete response to treatment. In this group, 9 of 11 patients who responded to treatment also had a significant reduction in CTN. Eight of these 9 patients then had tumour relapse, with a subsequent rise in CTN concentration. However, this rise was only moderate, albeit disease symptoms were clinically significant, indicating that CTN was not a useful prognostic marker. The results suggested that only in a small proportion of patients would CTN be of prognostic value, but no consistent patient characteristics were identified. Only three patients with hypercalcitonaemia in remission were followed up to 18 months after treatment initiation.
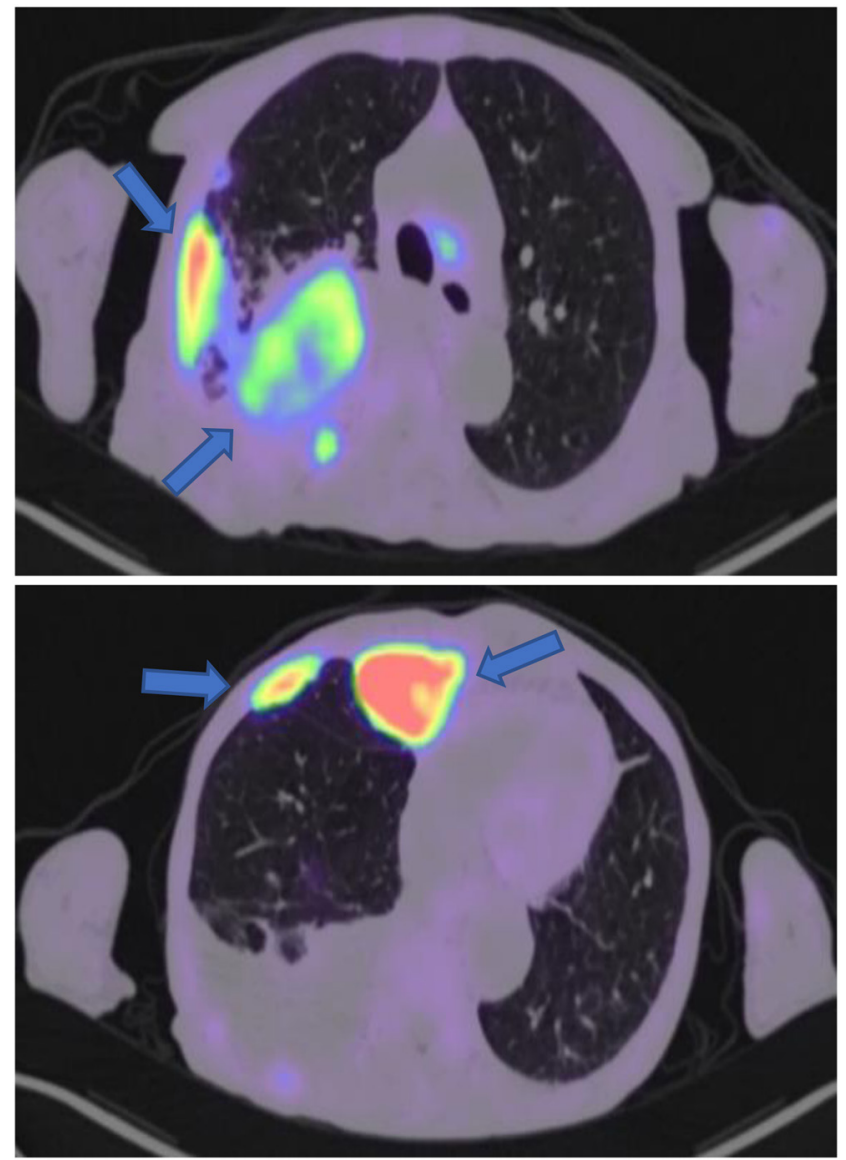

Figure 6

${ }^{68} \mathrm{Ga}$-DOTATATE PET/CT scan with arrows pointing to the upper lobe primary, pleural and nodal disease. 


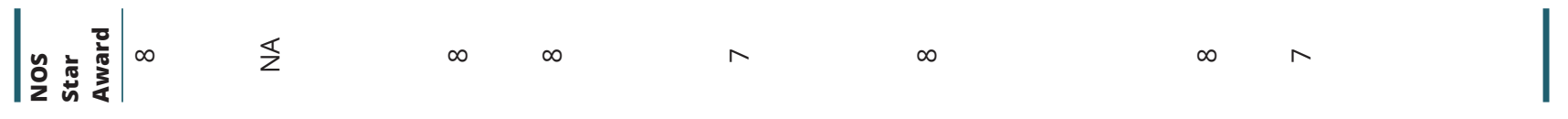

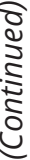

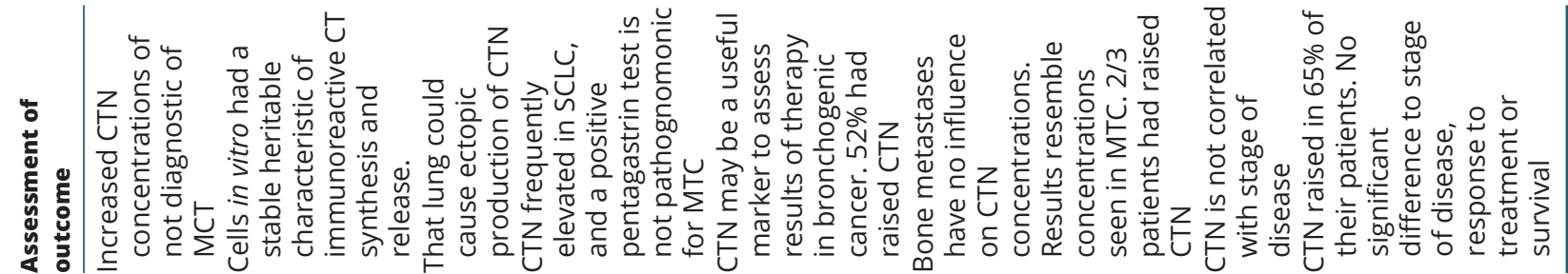
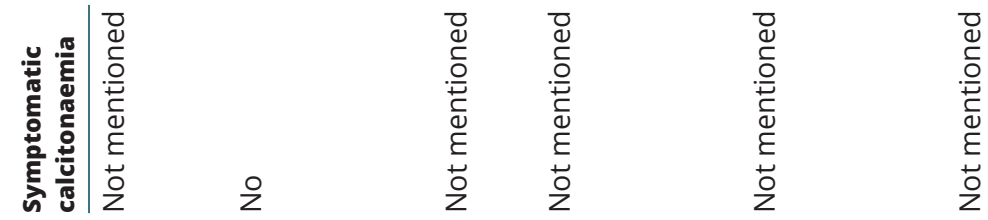

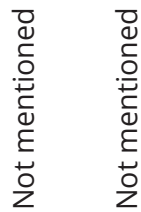
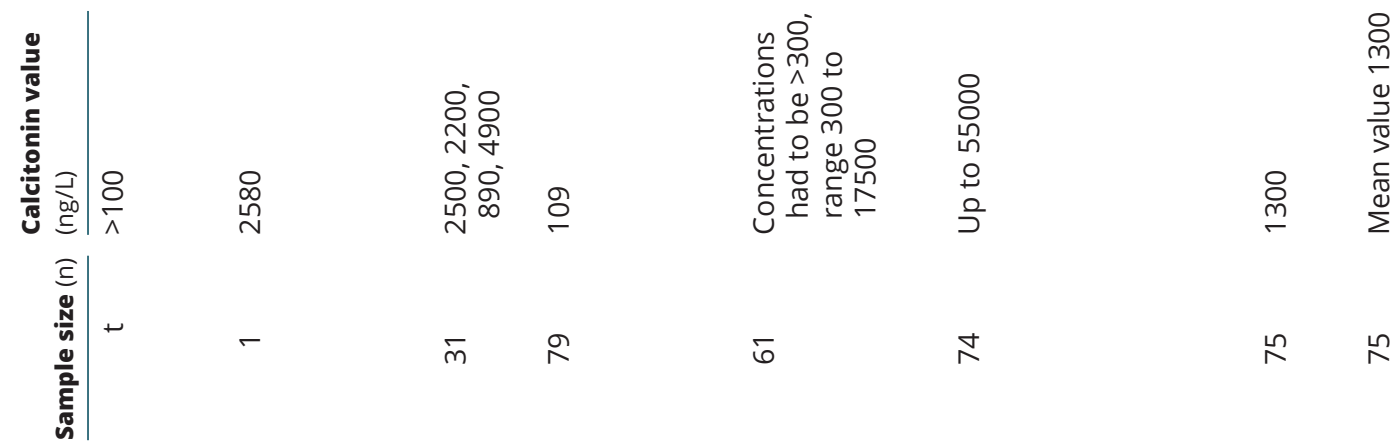

$\bar{m} \quad r$

$\overline{6}$

辛

$\stackrel{n}{\wedge} \stackrel{n}{\wedge}$

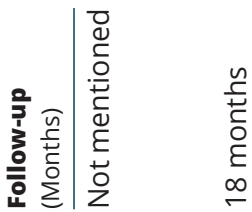

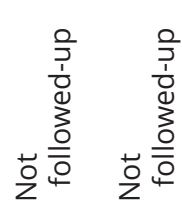

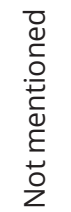

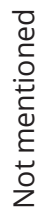

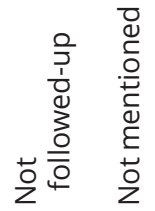

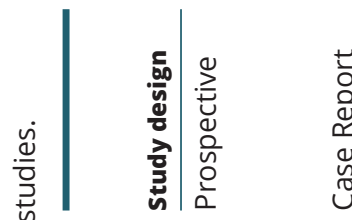
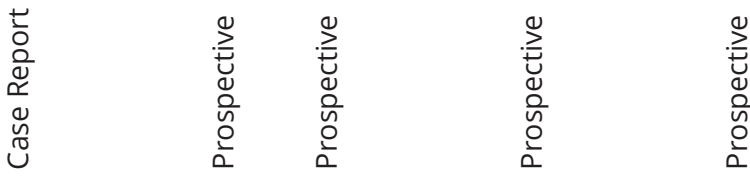

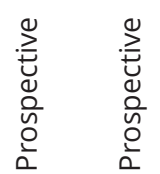

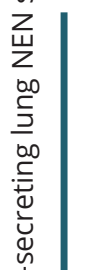
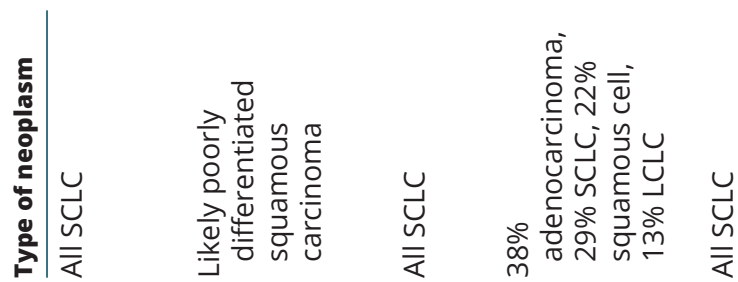

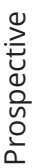
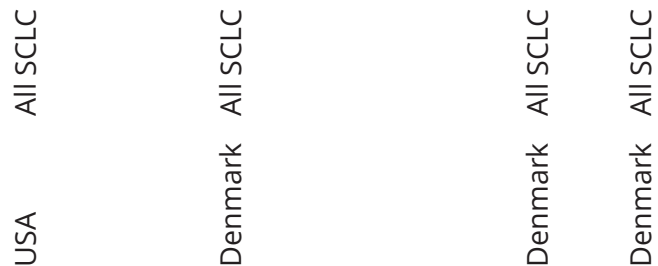

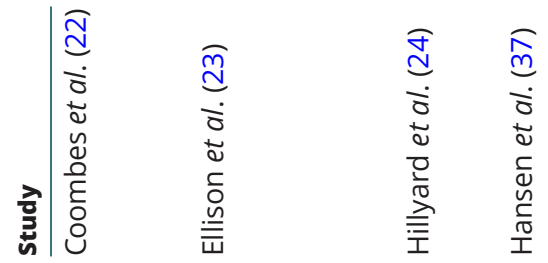

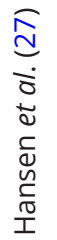

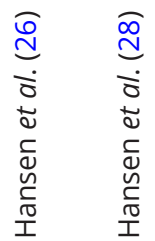


|

$\infty$

$\stackrel{\$}{z} \quad \infty \quad \frac{5}{z}$

$\infty$

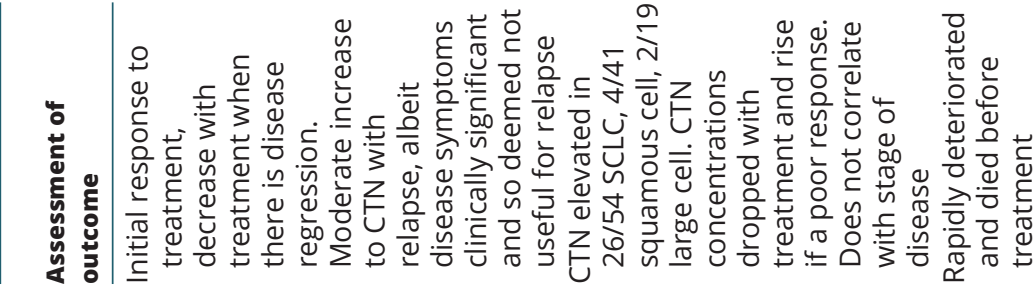

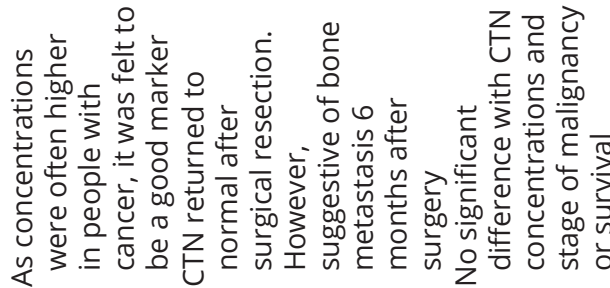

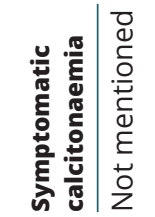

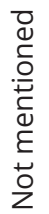
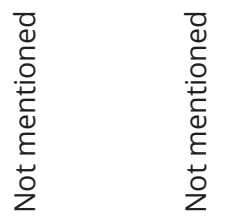

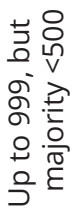
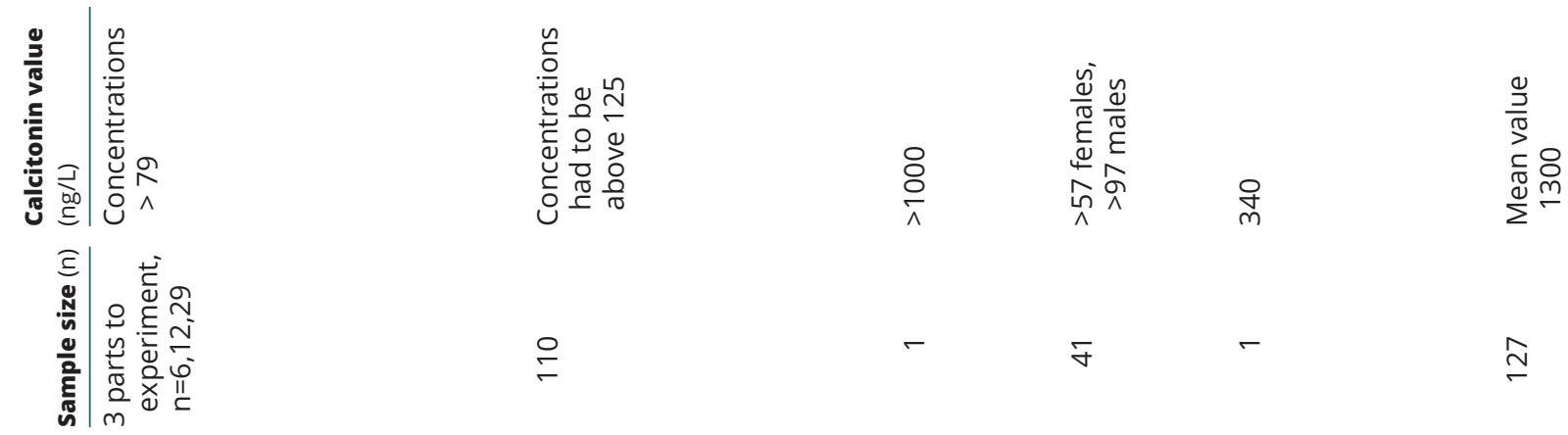

$\stackrel{ }{ }$

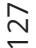

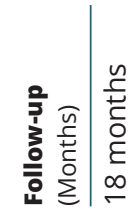

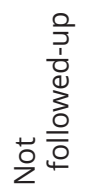

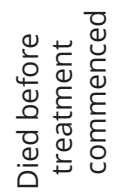

$\frac{\frac{0}{3}}{\frac{1}{0}}$

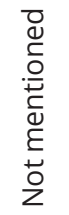

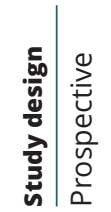

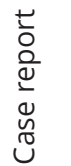
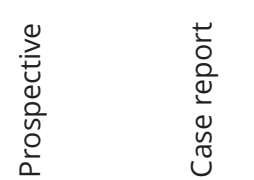

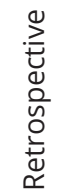
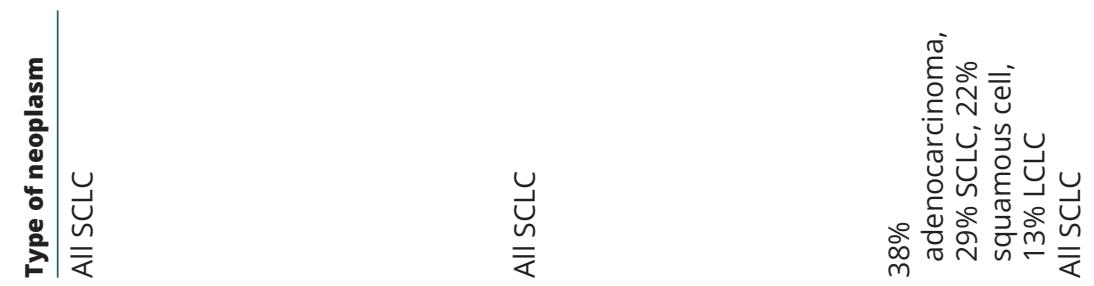

|

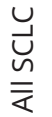

$\stackrel{\cup}{\breve{U}}$

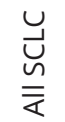

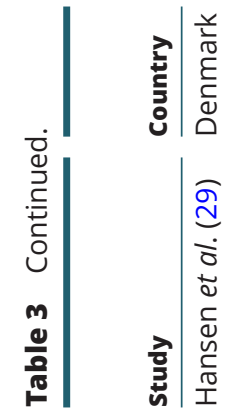

空

芩

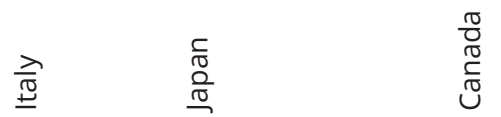

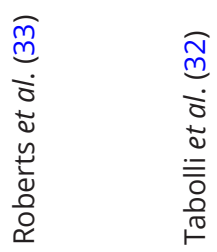

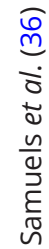




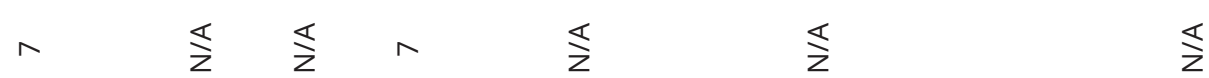

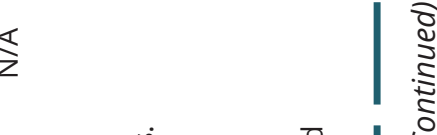

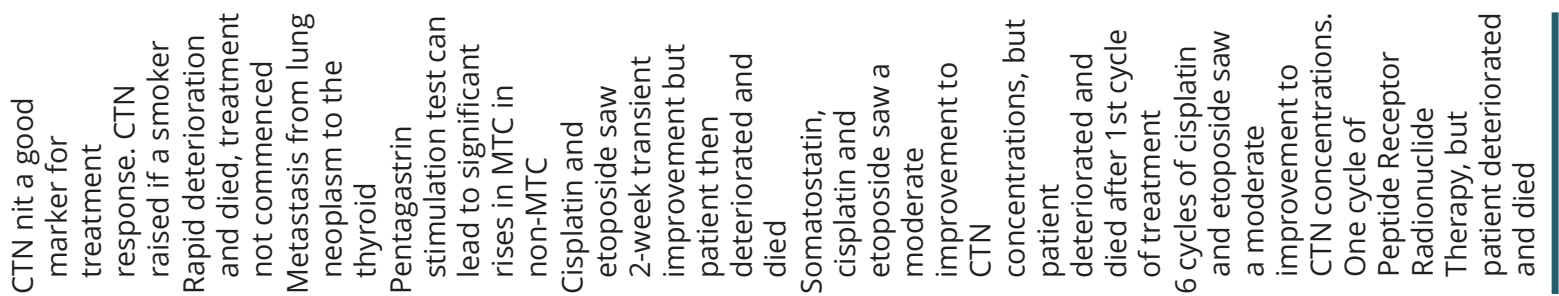

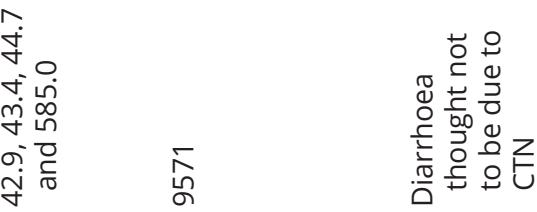

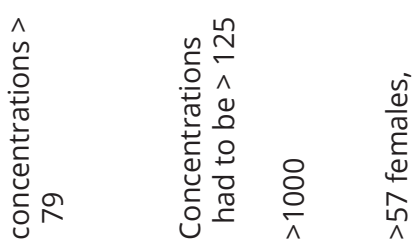

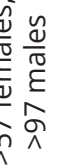

$\stackrel{ }{m}$

$\stackrel{\infty}{\infty}$

$\stackrel{\circ}{N}$

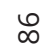

$\stackrel{m}{r}$

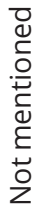

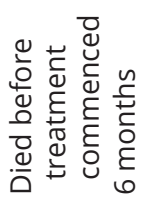

$\frac{\frac{3}{3}}{\frac{1}{d}}$
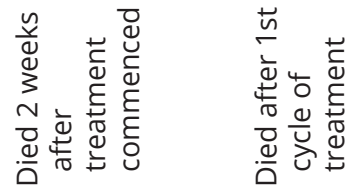

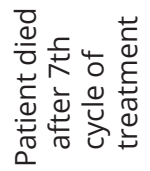

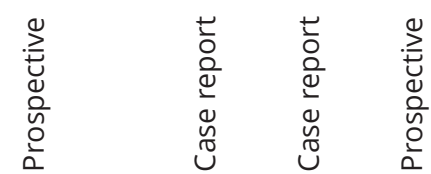

$\frac{T}{0}$
$\frac{0}{0}$
$\stackrel{0}{0}$
$\tilde{U}$

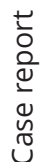

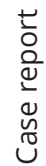

$\stackrel{\cup}{\stackrel{u}{\varangle}} \quad$

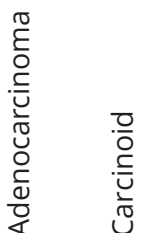

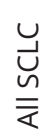

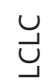

己ّ

岂

药 $\quad \frac{\varepsilon}{3}$

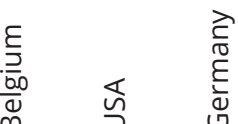

气

ฐิ

$\stackrel{\frac{\pi}{0}}{\frac{0}{2}}$

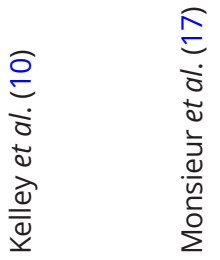

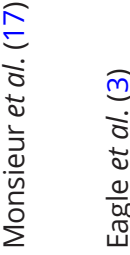

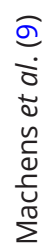

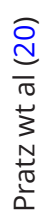

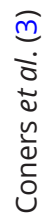

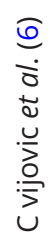




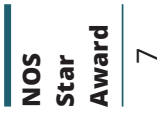

$\S \infty$
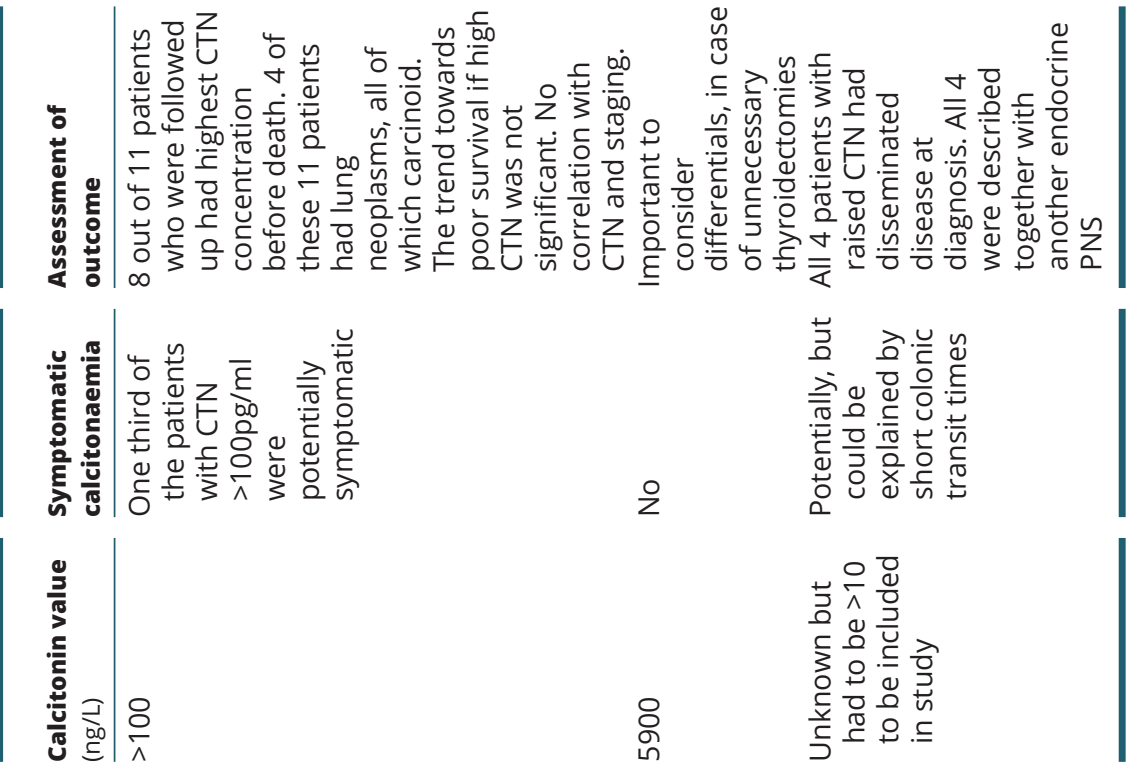

우

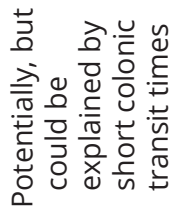

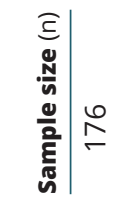

오ํ
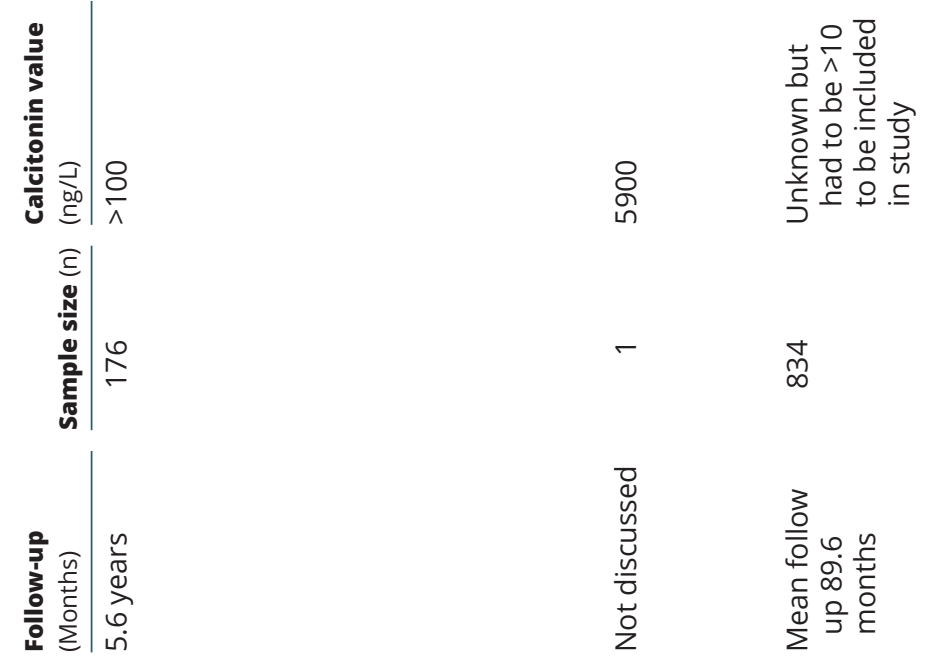

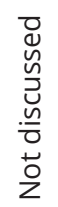

$\underset{\infty}{\mathbb{\infty}}$

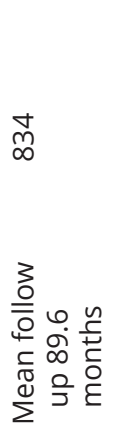

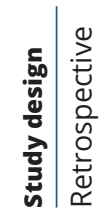
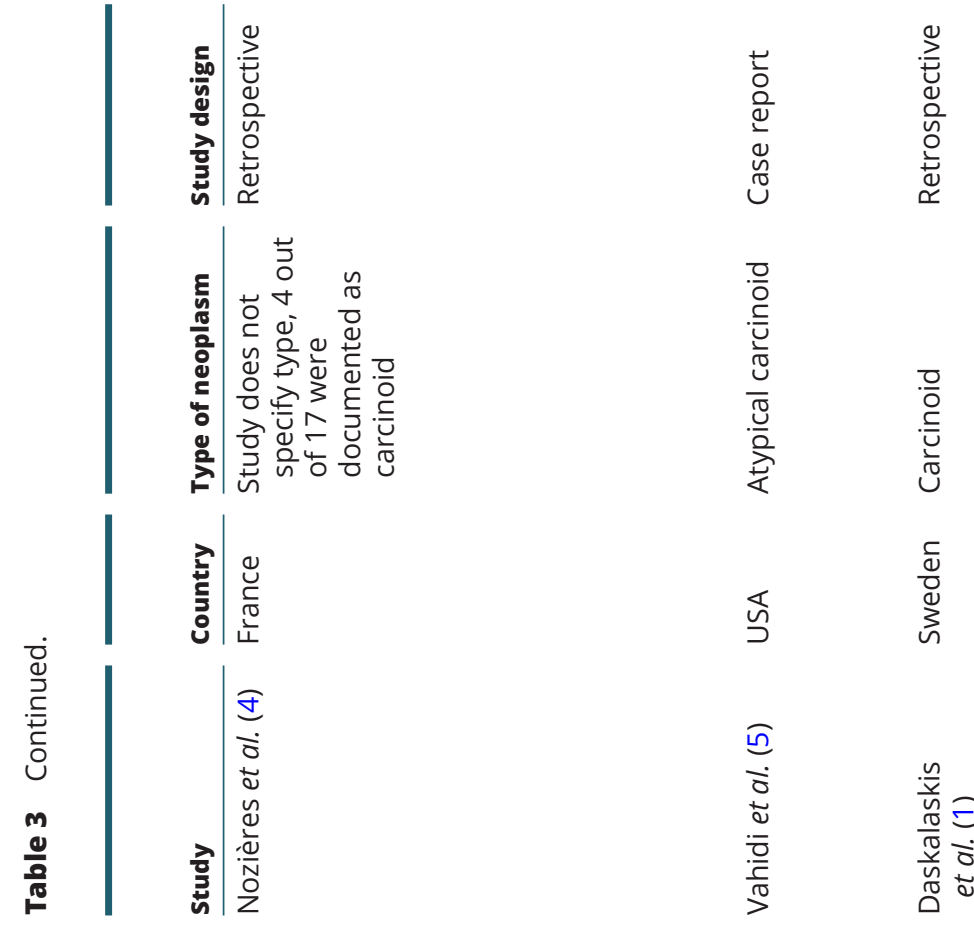

\begin{tabular}{l}
$\frac{0}{0}$ \\
$\frac{0}{0}$ \\
$\frac{0}{0}$ \\
$\frac{0}{0}$ \\
$\frac{0}{20}$ \\
\hline$\frac{10}{4}$
\end{tabular}

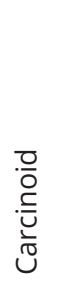

药 离
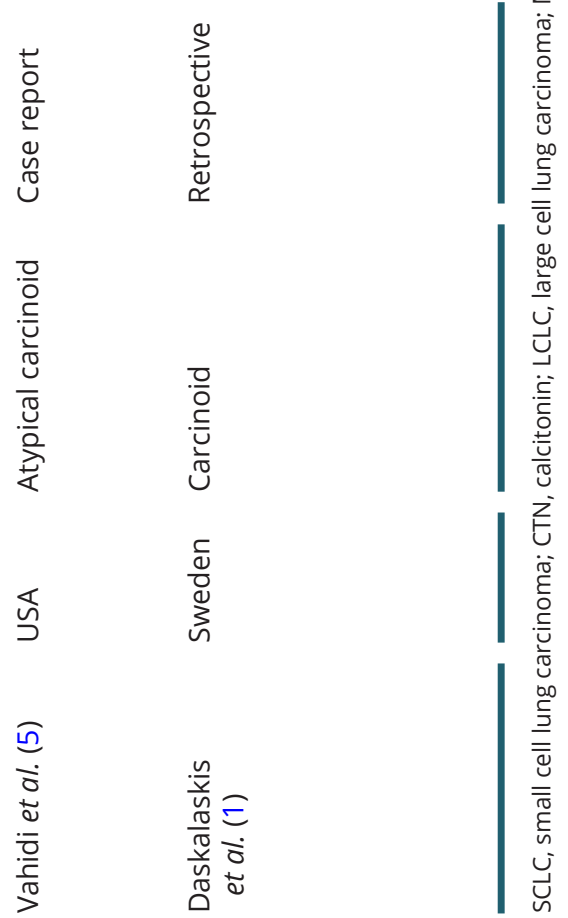
Their CTN concentrations had only been moderately increased at baseline and remained stable after 18 months follow-up.

Gropp et al. used a higher pathological CTN cut off ( $>125 \mathrm{pg} / \mathrm{mL}$ ), and abnormal results were observed in 26 out of 54 patients with SCLC. There was no positive or negative correlation to disease stage (30). CTN concentrations would decrease if there was a good response to treatment and rise in poor responders but findings were only numerically significant. In a study by Coombes et al., while higher baseline serum CTN values were associated with a poorer response to treatment, it was recommended that measuring serum CTN to predict response to treatment should be kept to a minimum (31).

Tabolli et al. reported a high incidence of hypercalcitonaemia, with $53.6 \%$ of their 41 bronchogenic carcinomas showing a raised CTN, but unlike Gropp et al. they did not provide information regarding their histopathological characteristics (32). As concentrations were regularly increased in patients with malignant neoplasms, CTN was felt to be a useful marker.

Roberts et al. presented a case of a patient with hypercalcitonaemia and amylase co-secretion. The patient also had raised adrenocorticotrophic hormone (ACTH), raised growth hormone, and raised luteinising hormone (33). Sano et al. discuss a patient with lung carcinoid co-secreting somatostatin and CTN (34). A particularly rare case of ectopic co-secretion of six hormones including CTN from one tumour was reported by Monsieur et al. (17). Melanin production in MTC and lung carcinoid tumours leading to diagnostic uncertainty has been reported by Eagle et al. (35). Initially, the diagnosis was thought to be primary amelanotic choroidal melanoma with choroidal metastases. However, detailed investigations confirmed a primary lung carcinoid (35).

In a study of patients with untreated SCLC, Samuels et al. demonstrated no relationship between CTN concentration and disease stage or survival rate (36). On review of previous studies, they estimated that $25-66 \%$ of patients with SCLC have elevated CTN concentrations at the time of diagnosis; $71 \%$ of their 69 patients had elevated CTN, but the only significant result found was hypercalcitonaemia in liver metastases, with hypercalcitonaemia having a sensitivity of $100 \%$ but a specificity of only $41 \%$ and a positive predictive value of $40 \%$. As with Hansen et al., there was no significant difference in CTN concentrations in case of metastatic bone disease (27).

Kelley et al. designed a study with 3 arms, including non-smokers without SCLC, smokers without SCLC, and smokers with SCLC (10). All but one of the 49 patients smoked in the SCLC group. They were able to demonstrate that in the two groups without SCLC, smoking appeared to moderately increase CTN. Kelley et al. also demonstrated in a murine animal model that air pollution or smoking increased the number of pulmonary neuroendocrine cells that were positive for CTN on immunohistochemical staining, and that smoking appeared to cause hyperplasia of the pulmonary neuroendocrine cells. In their human study, CTN concentrations were not correlated with the severity of smoking. Interestingly, 6 patients with SLCL had negative staining for CTN on immunohistochemistry, but elevated serum CTN. Like in other cases of PNS with peripherally raised hormone but negative staining, one theory for this may be that SCLC cells may have acquired the ability to secrete CTN but have not completely altered their machinery to express this histologically. It was concluded that the use of CTN was not a reliable marker for monitoring treatment response (10).

Interestingly, on immunohistochemical studies of 2 of the reported studies reported in Table 3, there was negative CTN tissue staining but raised serum levels, similar to the findings of Kelley et al. (10, 11, 20). Pratz et al. (20) hypothesised that large cell lung carcinoma (LCLC) cases they described co-secreted VIP and CTN. One theory was that LCLC tumours from their study were biologically behaving like a VIPoma, in which cells rapidly secrete CTN reaching high serum concentrations, and so may not be seen expressed within the tumour cells. An alternative theory was that the neoplasm secretes an as yet unknown substance that stimulates CTN secretion from C cells. Whilst there can be other causes of hypercalcitonaemia $(7,8,10)$, these would not induce CTN elevation as such reported by Pratz et al. (20).

Coners et al. reported the first case of SCLC co-secreting ACTH and CTN (3). Cvijovic et al. presented a patient with multinodular goitre, neck lymphadenopathy, raised CTN and raised carcinoembryonic antigen (CEA), who was referred to them initially with the diagnosis of MTC (7). Surgical excision of the lymph node showed this to be a metastasis from a neuroendocrine neoplasm, with bronchoscopy confirming the diagnosis (7).

Similarly, Vahidi et al. report a case of suspected MTC but with an incidental lung lesion seen on a chest X-ray and biopsy suggesting either MTC or other NEN. Both cases by Cvijovic et al. and Vahidi et al. are similar to our case as thyroid FNA was required to help rule out $\operatorname{MTC}(6,7)$.

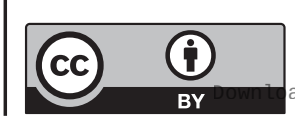

This work is licensed under a Creative Commons Attribution 4.0 International License. ded from Bioscientifica.com at 04/26/2023 10:32:39AM 
Daskalaskis et al. performed a large retrospective study of more than 700 patients with NENs to describe the incidence of endocrine paraneoplastic syndromes (2). Only four patients were found to have hypercalcitonaemia, but the study included patients with multiple NEN sites not just originating from the lung. One of these patients was documented as having a lung carcinoid. All four patients had stage IV disease, and all four were described as having concurrently other endocrine PNS with hypercalcitonaemia. This study highlights the rarity of lung NENs-secreting CTN (2).

Machens et al. and Hansen et al., focused on the use of CTN stimulation tests to look at whether CTN-secreting NENs can be distinguished from MTC based on response to calcium or pentagastrin tests. Whilst Machens et al. suggested that MTC tends to be associated with a doubling CTN concentration following stimulation, Hansen et al. warned that there can still be a significant CTN rise in lung NENs, and that high CTN response to stimulation is not pathognomonic for $\operatorname{MTC}(9,37)$. In this study, 54 of the 79 patients had hypercalcitonaemia prior to pentagastrin test, with $25 \%$ of them having CTN concentrations expected of MTC.

In the largest recent study of CTN-secreting NENs, Nozières et al. reviewed the data of 17 patients with lung NENs-secreting CTN (5). Nine of these patients had high CTN concentrations over $100 \mathrm{ng} / \mathrm{L}$ at diagnosis. Whilst Nozières et al. did not demonstrate an association between CTN concentrations and prognosis, patients whose CTN concentration was $>100 \mathrm{ng} / \mathrm{L}$ had higher grade neoplasms. They suggest testing for CTN in patients with foregut NENs and diarrhoea (5).

\section{Conclusions}

This work highlights the importance of considering differentials toMTCwhen presented with thyroid pathology and hypercalcitonaemia, and that although raised serum calcitonin suggests MTC, it is not pathognomonic. Our review of the literature highlights conflicting results when interpreting CTN role in predicting biological behaviour, response to treatment or overall survival rates in cases of patients with ectopic hypercalcitonaemia to lung NENs. The interpretation of elevated serum calcitonin is still a matter of debate given the many confounding factors, variety of assays with limited efficacy and different cutoffs. We propose a thorough clinical evaluation of all patients presenting with elevated CTN concentration followed by multidisciplinary discussion when planning investigations and therapy to avoid misdiagnosis of ectopic CTN sources of secretion.

\section{Declaration of interest}

The authors declare that there is no conflict of interest that could be perceived as prejudicing the impartiality of the research reported.

\section{Funding}

National Institute for Health Research (NIHR), South London Clinical Research Network (CRN) Strategic 'Green shoots' Investigator Award supported Dr Dimitriadis in the writing of this manuscript.

\section{Acknowledgements}

The authors of this manuscript sought to locate family members and therefore ask permission to publish this fully anonymised report after this patient died but were unsuccessful in locating them. The authors of this manuscript report no conflicting interests.

\section{References}

1 Dimitriadis GK, Angelousi A, Weickert MO, Randeva HS, Kaltsas G \& Grossman A. Paraneoplastic endocrine syndromes. Endocrine-Related Cancer 201724 R173-R190. (https://doi.org/10.1530/ERC-17-0036)

2 Daskalakis K, Chatzelis E, Tsoli M, Papadopoulou-Marketou N, Dimitriadis GK, Tsolakis AV \& Kaltsas G. Endocrine paraneoplastic syndromes in patients with neuroendocrine neoplasms. Endocrine 201964 384-392. (https://doi.org/10.1007/s12020-018-1773-3)

3 Coners K, Woods SE \& Webb M. Dual paraneoplastic syndromes in a patient with small cell lung cancer: a case report. Journal of Medical Case Reports 20115 318. (https://doi.org/10.1186/1752-1947-5-318)

4 Nozières C, Chardon L, Goichot B, Borson-Chazot F, Hervieu V, Chikh K, Lombard-Bohas C \& Walter T. Neuroendocrine tumors producing calcitonin: characteristics, prognosis and potential interest of calcitonin monitoring during follow-up. European Journal of Endocrinology 2016174 335-341. (https://doi.org/10.1530/EJE-150917)

5 Vahidi S, Stewart J, Amin K, Racila E \& Li F. Metastatic medullary thyroid carcinoma or calcitonin-secreting carcinoid tumor of lung? A diagnostic dilemma in a patient with lung mass and thyroid nodule. Diagnostic Cytopathology 201846 345-348. (https://doi.org/10.1002/ dc.23852)

6 Cvijovic G, Micic D, Kendereski A, Zoric S, Sumarac-Dumanovic M, Tatic S, Trivic A, Pejkovic-Stamenkovic D \& Jeremic D. Ectopic calcitonin secretion in a woman with large cell neuroendocrine lung carcinoma. Hormones 201312 584-590. (https://doi.org/10.14310/ horm.2002.1447)

7 Giannetta E, Guarnotta V, Altieri B, Sciammarella C, Guadagno E, Malandrino P, Puliani G, Feola T, Isidori AM, Colao AAL, et al. ENDOCRINE TUMOURS: Calcitonin in thyroid and extra-thyroid neuroendocrine neoplasms: the two-faced Janus. European Journal of Endocrinology 2020183 R197-R215. (https://doi.org/10.1530/EJE-200506)

8 Gambardella C, Offi C, Clarizia G, Romano RM, Cozzolino I, Montella M, Di Crescenzo RM, Mascolo M, Cangiano A, Di Martino S, et al. Medullary thyroid carcinoma with double negative calcitonin and CEA: a case report and update of literature review. BMC Endocrine Disorders 201919 103. (https://doi.org/10.1186/ s12902-019-0435-7)

9 Machens A, Haedecke J, Holzhausen HJ, Thomusch O, Schneyer U \& Dralle H. Differential diagnosis of calcitonin-secreting

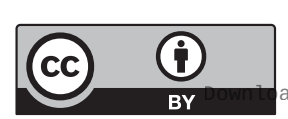

This work is licensed under a Creative Commons Attribution 4.0 International License. 
neuroendocrine carcinoma of the foregut by pentagastrin stimulation. Langenbeck's Archives of Surgery 2000385 398-401. (https://doi.org/10.1007/s004230000169)

10 Kelley MJ, Becker KL, Rushin JM, Venzon D, Phelps R, Ihde DC, Bliss DP, Melby K, Snider RH \& Johnson BE.Calcitonin elevation in small cell lung cancer without ectopic production. American Journal of Respiratory and Critical Care Medicine 1994149 183-190. (https:// doi.org/10.1164/ajrccm.149.1.8111580)

11 Ghillani PP, Motté P, Troalen F, Jullienne A, Gardet P, Le Chevalier T, Rougier P, Schlumberger M, Bohuon C \& Bellet D. Identification and measurement of calcitonin precursors in serum of patients with malignant diseases. Cancer Research 198949 6845-6851.

12 Sui P, Wiesner DL, Xu J, Zhang Y, Lee J, Van Dyken S, Lashua A, Yu C, Klein BS, Locksley RM, et al. Pulmonary neuroendocrine cells amplify allergic asthma responses. Science 2018360 eaan8546. (https://doi. org/10.1126/science.aan8546)

13 Naizhen X, Linnoila RI \& Kimura S. Co-expression of achaete-scute homologue-1 and calcitonin gene-related peptide during NNKinduced pulmonary neuroendocrine hyperplasia and carcinogenesis in hamsters. Journal of Cancer 20167 2124-2131. (https://doi. org/10.7150/jca.16399)

14 Weichselbaum M, Sparrow MP, Hamilton EJ, Thompson PJ \& Knight DA. A confocal microscopic study of solitary pulmonary neuroendocrine cells in human airway epithelium. Respiratory Research 20056 115. (https://doi.org/10.1186/1465-9921-6-115)

15 Song H, Yao E, Lin C, Gacayan R, Chen MH \& Chuang PT. Functional characterization of pulmonary neuroendocrine cells in lung development, injury, and tumorigenesis. PNAS 2012109 17531-17536. (https://doi.org/10.1073/pnas.1207238109)

16 Gosney JR, Sissons MC \& Allibone RO. Neuroendocrine cell populations in normal human lungs: a quantitative study. Thorax 198843 878-882. (https://doi.org/10.1136/thx.43.11.878)

17 Monsieur I, Meysman M, Noppen M, de Greve J, Delhove O, Velckeniers B, Jacobvitz D \& Vincken W. Non-small-cell lung cancer with multiple paraneoplastic syndromes. European Respiratory Journal 19958 1231-1234. (https://doi.org/10.1183/09031936.95.08071231)

18 Mitchell AL, Gandhi A, Scott-Coombes D \& Perros P. Management of thyroid cancer: United Kingdom National Multidisciplinary Guidelines. Journal of Laryngology and Otology 2016130 (Supplement 2) S150-S160. (https://doi.org/10.1017/S0022215116000578)

19 Bondy PK. The pattern of ectopic hormone production in lung cancer. Yale Journal of Biology and Medicine 1981 54 181-185.

20 Pratz KW, Ma C, Aubry MC, Vrtiska TJ \& Erlichman C. Large cell carcinoma with calcitonin and vasoactive intestinal polypeptideassociated Verner-Morrison syndrome. Mayo Clinic Proceedings 2005 80 116-120. (https://doi.org/10.1016/S0025-6196(11)62968-6)

21 Tsutsumi Y. Immunohistochemical analysis of calcitonin and calcitonin gene-related peptide in human lung. Human Pathology 198920 896-902. (https://doi.org/10.1016/0046-8177(89)90103-2)

22 Coombes RC, Hillyard C, Greenberg PB \& MacIntyre I. Plasmaimmunoreactive-calcitonin in patients with non-thyroid tumours. Lancet 19741 1080-1083. (https://doi.org/10.1016/s01406736(74)90557-1)

23 Ellison M, Woodhouse D, Hillyard C, Dowsett M, Coombes RC, Gilby ED, Greenberg PB \& Neville AM. Immunoreactive calcitonin production by human lung carcinoma cells in culture. British Journal of Cancer 197532 373-379. (https://doi.org/10.1038/bjc.1975.237)
24 Hillyard CJ, Coombes RC, Greenberg PB, Galante LS \& MacIntyre I. Calcitonin in breast and lung cancer. Clinical Endocrinology 19765 1-8. (https://doi.org/10.1111/j.1365-2265.1976.tb03797.x)

25 Silva OL, Broder LE, Doppman JL, Snider RH, Moore CF, Cohen MH \& Becker KL. Calcitonin as a marker for bronchogenic cancer: a prospective study. Cancer 1979 44 680-684. (https://doi.org/10.1002/1097-0142(197908)44:2<680::aidcncr2820440240>3.0.co;2-j)

26 Hansen M, Hansen HH, Hirsch FR, Arends J, Christensen JD, Christensen JM, Hummer L \& Kühl C. Hormonal polypeptides and amine metabolites in small cell carcinoma of the lung, with special reference to stage and subtypes. Cancer 198045 1432-1437. (https://doi.org/10.1002/1097-0142(19800315)45:6<1432::aidcncr2820450622>3.0.co;2-z)

27 Hansen M, Rehfeld JF \& Stadil F. Small cell carcinoma of the lung: relation of calcitonin to bone marrow metastases, parathormone and gastrin. Acta Medica Scandinavica 1979206 215-218. (https://doi. org/10.1111/j.0954-6820.1979.tb13497.x)

28 Hansen M, Hammer M \& Hummer L. Diagnostic and therapeutic implications of ectopic hormone production in small cell carcinoma of the lung. Thorax 198035 101-106. (https://doi.org/10.1136/ thx.35.2.101)

29 Hansen M, Hammer M \& Hummer L. ACTH, ADH, and calcitonin concentrations as markers of response and relapse in small-cell carcinoma of the lung. Cancer 198046 2062-2067. (https://doi.org/10.1002/1097-0142(19801101)46:9<2062::AIDCNCR2820460926>3.0.CO;2-X)

30 Gropp C, Havemann K \& Scheuer A. Ectopic hormones in lung cancer patients at diagnosis and during therapy. Cancer 198046 347-354. (https://doi.org/10.1002/1097-

0142(19800715)46:2<347::aid-cncr2820460223>3.0.co;2-s)

31 Coombes RC, Dearnaley DP, Ellison ML \& Neville AM. Markers in breast and lung cancer. Annals of Clinical Biochemistry 198219 263-268. (https://doi.org/10.1177/000456328201900415)

32 Tabolli S, Valtorta C, Scarda A, D'Erasmo E, Minisola S, Antonelli R, Medori C \& Mazzuoli G. Plasma calcitonin and tumors. Tumori 1983 69 227-230. (https://doi.org/10.1177/030089168306900310)

33 Roberts I, Chopra S \& Warshaw AL. Carcinoma of the lung with marked hyperamylasemia and elevated serum calcitonin. American Journal of Gastroenterology 198277 43-44.

34 Sano T, Saito H, Yamasaki R, Hamaguchi K, Ooiwa K, Shimoda T, Hosoi E, Saito S \& Hizawa K. Immunoreactive somatostatin and calcitonin in pulmonary neuroendocrine tumor. Cancer $1986 \mathbf{5 7}$ 64-68. (https://doi.org/10.1002/1097-0142(19860101)57:1<64::aidcncr2820570114>3.0.co;2-6)

35 Eagle RC Jr, Ehya H, Shields JA \& Shields CL. Choroidal metastasis as the initial manifestation of a pigmented neuroendocrine tumor. Archives of Ophthalmology 2000118 841-845. (https://doi. org/10.1001/archopht.118.6.841)

36 Samuels T, Cameron R, Hirte H, Osoba D, Malkin DG \& Malkin A Imaging studies and the prognostic value of serum calcitonin in staging small-cell lung cancer. Tumour Biology 19878 211-217. (https://doi.org/10.1159/000217524)

37 Hansen M, Hansen HH \& Tryding N. Small cell carcinoma of the lung: serum calcitonin and serum histaminase (diamine oxidase) at basal levels and stimulated by pentagastrin. Acta Medica Scandinavica 1978204 257-261. (https://doi.org/10.1111/j.0954-6820.1978. tb08436.x)

Received in final form 16 February 2021

Accepted 24 March 2021

Accepted Manuscript published online 25 March 2021 https://ec.bioscientifica.com https://doi.org/10.1530/EC-21-0071 (c) 2021 The authors Published by Bioscientifica Ltd

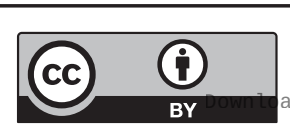

This work is licensed under a Creative Commons Attribution 4.0 International License. ded from Bioscientifica.com at 04/26/2023 10:32:39AM 